\title{
Nosocomial Pneumonia Associated to PVL-Producing Staphylococcus aureus in Children in Benin
}

\author{
Lamine Baba-Moussa, ${ }^{1}$ Théodora Angèle Ahoyo, ${ }^{2}$ Cécile Le Brun, ${ }^{3}$ Michel Makoutodé, ${ }^{4}$ \\ Karim Dramane, ${ }^{5}$ Simeon Oloni Kotchoni, ${ }^{6}$ and Gilles Prévost ${ }^{3}$ \\ ${ }^{1}$ Laboratoire de Biologie et de Typage Moléculaire en Microbiologie, Département de Biochimie et de Biologie Cellulaire, \\ Faculté des Sciences et Techniques, Université d'Abomey-Calavi, 05 BP 1604 Cotonou, Benin \\ ${ }^{2}$ Laboratoire de Biologie Humaine, Ecole Polytechnique d'Abomey-Calavi, Université d'Abomey-Calavi, 01 BP 526 Cotonou, Benin \\ ${ }^{3}$ Institut de Bactériologie, Université de Strasbourg, Unité: EA-4438 Physiopathologie et Médecine, 3 rue Koeberlé, \\ 67000 Strasbourg, France \\ ${ }^{4}$ Institut Régional de Santé Publique, Université d'Abomey-Calavi, BP 384 Ouidah, Benin \\ ${ }^{5}$ Laboratoire de Pharmacologie Cellulaire, Faculté des Sciences et Techniques, Université d'Abomey-Calavi, Benin \\ ${ }^{6}$ Department of Biology and Center for Computational and Integrative Biology, Rutgers, The State University of New Jersey, \\ 315 Penn Street, Camden, NJ 08102, USA
}

Correspondence should be addressed to Lamine Baba-Moussa; laminesaid@yahoo.fr

Received 19 June 2013; Accepted 15 July 2013

Academic Editors: D. Bachani and A. Carvalho

Copyright (C) 2013 Lamine Baba-Moussa et al. This is an open access article distributed under the Creative Commons Attribution License, which permits unrestricted use, distribution, and reproduction in any medium, provided the original work is properly cited.

\begin{abstract}
We determined the type of toxins produced by Staphylococcus aureus strains and the possible source of contamination during an outbreak of nosocomial pneumonia in a Paediatric service in Benin. Data of 37 patients admitted in the malnourished unit who were diagnosed with pneumonia according to WHO definition and with radiological evidence of a pulmonary infiltrate were collected within six weeks. Pneumonia was further confirmed by the identification of corresponding pneumonia-related S. aureus. Samples were also collected from hospital personnel, the environment, and the food fed to the patients. Pulsed field gel electrophoresis (PFGE) was used to compare the bacterial profile from different sources. Among the 37 patients admitted during this period, 17 developed pneumonia and 10 were associated with S. aureus strains. Nine patients infected with S. aureus PVL-producing strains had underlying diseases and developed an acute multilobar pneumonia, which was fulminating and rapidly became fatal in all except the oldest child. Most of the isolates found on sick children were similar to those from special nutrients consumed by children and on the personnel at the hospital. The highly probable relationships between children contamination and isolate presence in the special nutrient underline the rapid and disastrous dissemination of some PVL-producing isolates in this paediatric unit.
\end{abstract}

\section{Introduction}

Staphylococcus aureus is the causal agent of various community-acquired or nosocomial infections [1]. Among the infections, pneumonia generally represents $1 \%$ of community cases and $10 \%$ of nosocomial cases in the developed countries [2]. S. aureus may secrete more than forty different toxins and enzymes, as well as numerous adhesion factors depending on the strains. One of the common toxins, the Panton-Valentine leukocidin (PVL) is frequently associated with furuncles $[3,4]$. A series of skin infections due to PVL-producing leukocidin isolates occurring in nurseries or paediatric units have been reported $[4,5]$. The first isolations of methicillin-sensitive strains associated with pneumonia carrying bacteriophages $80 / 81$ were reported in the eighties [6]. PVL-producing strains were shown to be responsible for necrotizing community-acquired pneumonia in teenagers and young adults [7-11], while young infants and neonates are rarely affected by this disease $[5,12,13]$. Recently, the role of PVL in these diseases was carried out in experimental models [14]. It was suggested to be probably one of the essential factors of the disease establishment.

Pneumonia is a leading cause of childhood mortality in sub-Saharan Africa [15]. Concurrently, a higher incidence 
of PVL-producing isolates for both nosocomial and community-acquired infections has been reported [16-18], while fewer clinical observations of community-acquired pneumonia have been reported in children [19].

In 2009, a series of cases of pneumoniasuddenly appeared among malnourished children in the paediatrics unit at the Zou/Collines Department Hospital Centre (CHDZ/C), Benin and $S$. aureus was often diagnosed. This prompted the medical personal to search for the source of the outbreak. That is the reason for this study.

\section{Material and Methods}

2.1. Ethics Statement. Ethical clearance was obtained from the Ministry of Public Health of Benin under protocol number 2959/MSP/DC/SG/DRH/SPREA-05-2002.

2.2. Patients and Clinical Data. A prospective study was carried out over a period of one month, (from September 5, 2009 to October 20, 2009) at the paediatrics unit of the Zou/ Collines Department Hospital Center (CHDZ/C) which has 55 beds devoted to malnourished children.

Included patients were hospitalized patients for more than 48 hours with clinical signs of pneumonia established according to the World Health Organization (WHO) clinical case definition which included cough and/or difficulty to breath with a raised respiratory rate ( $>60$ per $\mathrm{min}$ for individuals younger than 60 days $>50$ per min for those aged 60-64 days, $>40$ for those aged 1-5 years). Other clinical signs included fever $>38^{\circ} \mathrm{C}$, purulent expectorations, and radiological evidence of a pulmonary infiltrate characterized by novelty and progressiveness.

2.3. Hospital Sampling. Swabs including respiratory aspirates, blood, and pleural fluids samples were obtained from patients. Hands, nasopharynx, armpit, groin, and perineum swabs from healthcare workers comprising of 12 nurses, 6 physicians, and 7 other healthcare staff members were obtained using cotton stripped swabs. Environmental specimens were also collected from examination couches, stethoscope diaphragm, blood pressure armbands, telephones, and door latches. Foodborne controls were carried out twice a day (morning and afternoon).

2.4. S. aureus Identification. For the bacterial colony isolation, serial dilutions of the samples were made and diluted sample $(100 \mu \mathrm{L})$ was streaked on Baird-Parker agar supplemented with egg yolk tellurite enrichment suspension (Difco, Detroit, MI, US) and incubated at $37^{\circ} \mathrm{C}$ for 48 hours as previously described [20]. The physical identification characteristics of the bacterial colonies such as black, smooth, and convex to uniform outline with one or two halos were recorded [21]. S. aureus was confirmed by colonial morphology, Gram staining, catalase activity, and coagulation of citrated rabbit plasma (bioMérieux, Marcy l'Etoile, France) [22].
2.5. Antibiograms. Antimicrobial susceptibility was performed using agar disk diffusion method on Mueller Hinton agar according to the National Committee for Clinical Laboratory Standards (NCCLS) recommendations [23]. Interpretation of antimicrobial susceptibility followed the recommendations of the Antibiogram Committee of the French Microbiology Society (CA-SFM) [24]. Fourteen antibiotics were tested: Penicillin G $(6 \mu \mathrm{g})$, Oxacillin $(5 \mu \mathrm{g})$, Vancomycin $(30 \mu \mathrm{g})$, Teicoplanin $(30 \mu \mathrm{g})$, Fosfomycin $(50 \mu \mathrm{g})$, Rifampicin $(30 \mu \mathrm{g})$, Fusidic acid (10 $\mu \mathrm{g})$, Gentamicin (15 $\mu \mathrm{g})$, Trimethroprim Sulfamethoxazole $(1.25 / 23.75 \mu \mathrm{g})$, Pefloxacin $(5 \mu \mathrm{g})$, Pristinamycin $(15 \mu \mathrm{g})$, Erythromycin (15 UI), Tobramycin $(10 \mu \mathrm{g})$, and Chloramphenicol $(30 \mu \mathrm{g})$. Evaluation of methicillin resistance was performed by plating samples on buffered Mueller-Hinton agar with $2 \%(w / v) ~ N a C l$ at $37^{\circ} \mathrm{C}$ for $24 \mathrm{~h}$.

2.6. Identification of Leukotoxins, Epidermolysis and Enterotoxins. Two leukotoxins, PVL and LukE-LukD, were detected from culture supernatants by radial gel immunodiffusion using component-specific rabbit polyclonal but affinity-purified antibodies as previously described [25, 26]. Epidermolysins $\mathrm{A}$ and $\mathrm{B}$ were also determined as previously mentioned [26]. Enterotoxins A, B, C, D, and the TSST-1 were identified by using the SET- and TST-RPLA kits (Oxoid, Basingstoke, UK) [25, 27].

2.7. Pulsed Field Gel Electrophoresis (PFGE). PFGE was performed as previously described with a Beckman Geneline Transverse Alternating Field Electrophoresis (TAFE) system [28]. Pulsotypes were compared and were classified in a dendrogram by using the Dice coefficient and the unweighted pair group method with arithmetic mean clustering provided by Molecular Analyst (version 1.5) and Fingerprinting (version 1.12) software (Bio-Rad, Ivry sur Seine, France).

\section{Results}

3.1. Clinical Observations. A total of 36 children were hospitalized during the period of this study at CHDZ malnourished unit. All the patients had underlying diseases which were mainly acute malaria and typhoid fever and were treated with quinine and chloramphenicol. They were identified as moderately malnourished because their mean weight for age scores $(Z)$ were less than -2.00 as described by WHO statistics standards [29]. Seventeen (17) of them developed pneumonia, and 10 were associated with $S$. aureus, while the other 7 cases were associated with other bacteria. The 10 patients with $S$. aureus were numbered from patient no. 1 to no. 10 (Table 1). They were all hospitalized for more than 48 hours when they developed major clinical signs of a febrile pneumonia. Eight of them were initially admitted for malaria and 2 for typhoid fever (Table 1). All the 10 patients were young male children; eight of them were less than one year (3 to 11 months), one was 2 years old, and one was 7 years old. The underlying diseases rapidly led to malnutrition; thus, all patients received a specific cow-milk-based diet supplement 
TABLE 1: Clinical data of the 10 young infants concerned by pneumonia due to $S$. aureus.

\begin{tabular}{|c|c|c|c|c|c|c|}
\hline Patient age & Pathology at admission & $\begin{array}{l}\text { Time delay (days) } \\
\text { before pneumonia }\end{array}$ & $\begin{array}{l}\text { C reactive } \\
\text { protein }\end{array}$ & Pulsotype & $\begin{array}{l}\text { S. aureus Toxin } \\
\text { associated }\end{array}$ & $\begin{array}{c}\text { Evolution after } \\
\text { treatment }\end{array}$ \\
\hline No. $1-8$ mo. & Malaria marasmus & 15 & 96 & $\mathrm{AI}, \mathrm{Al}, 2$ & TSST-1 & Fatal 4 days \\
\hline No. 2-9 mo. & Malaria, Severe anaemia & 18 & 192 & AII, A3, 4, 6 & PVL & Fatal 15 days \\
\hline No. 3-24 mo. & $\begin{array}{l}\text { Typhoid fever, } \\
\text { Malnutrition }\end{array}$ & 23 & 96 & AII, A3, 4, 6 & PVL & Fatal 3 days \\
\hline No. 4-10 mo. & $\begin{array}{l}\text { Severe malaria } \\
\text { Crisis }\end{array}$ & 11 & 192 & AII, A3, 4, 6 & PVL & Fatal 7 days \\
\hline No. 5-9 mo. & Severe malaria & 15 & 96 & AII, A3, 4, 6 & PVL & Fatal 2 days \\
\hline No. 6-3 mo. & Typhoid fever & 18 & 96 & AII, A3, 4, 6 & PVL & Fatal 4 days \\
\hline No. 7-5 mo. & severe malaria & 15 & 192 & AII, A3, 4, 6 & PVL & Fatal 7 days \\
\hline No. 8-7 mo. & $\begin{array}{l}\text { Malaria and } \\
\text { Anaemia }\end{array}$ & 18 & 288 & AIII & PVL & Fatal 20 hours \\
\hline No. 9-7 y.o. & $\begin{array}{l}\text { Malaria and } \\
\text { Malnutrition }\end{array}$ & 7 & 192 & AII, A3, 4, 6 & PVL & $\begin{array}{l}\text { Rescue after blood } \\
\text { transfusion, leaving } \\
\text { hospital at day } 31, \\
\text { skin lesions }\end{array}$ \\
\hline No. $10-11 \mathrm{mo.}$ & Severe malaria & 16 & 192 & AII, A3, 4, 6 & & Fatal 5 days \\
\hline
\end{tabular}

TABLE 2: Distribution of S. aureus from hospital personnel and environment from September 5 to October 20, 2009.

\begin{tabular}{|c|c|c|c|c|c|}
\hline Origin & $\begin{array}{c}\text { Number of samples } \\
\text { analysed }\end{array}$ & $\begin{array}{c}\text { Number of } \\
\text { contaminated samples }\end{array}$ & $\begin{array}{l}\text { Number of } S \text {. aureus } \\
\text { positive samples }\end{array}$ & $\begin{array}{c}\text { Other } \\
\text { bacteria }\end{array}$ & $\begin{array}{c}\text { Number of } S \text {. aureus } \\
\text { PVL+ samples }\end{array}$ \\
\hline Special cold food & 150 & $\begin{array}{r}94 / 150 \\
(63 \%)\end{array}$ & $\begin{array}{c}65 / 150 \\
(43.33 \%)\end{array}$ & $\begin{array}{c}29 / 150 \\
(19.33 \%)\end{array}$ & $\begin{array}{c}32 / 65 \\
49 \%\end{array}$ \\
\hline Inanimate environment & 225 & $\begin{array}{l}59 / 225 \\
(26 \%)\end{array}$ & $\begin{array}{c}38 / 225 \\
(16.88 \%)\end{array}$ & $\begin{array}{c}21 / 225 \\
(9.33 \%)\end{array}$ & $\begin{array}{c}6 / 38 \\
(16 \%)\end{array}$ \\
\hline Personnel & 221 & $\begin{array}{l}75 / 221 \\
(34 \%)\end{array}$ & $\begin{array}{l}21 / 221 \\
(9.5 \%)\end{array}$ & $\begin{array}{c}54 / 221 \\
(24.43 \%)\end{array}$ & $\begin{array}{l}7 / 21 \\
33 \%\end{array}$ \\
\hline
\end{tabular}

PVL: Panton-Valentine leukocidin.

with cereals and vitamins, referred to as F75, F100 (Nutriset, Malaunay, France) [30]. Upon clinical examination, all the 10 patients showed symptoms of pleuropneumonia. A standard treatment was applied following WHO recommendations. Lung radiology (See examples in Figures 1(a), 1(b), 1(c), and $1(\mathrm{~d})$ ) revealed pyopneumothorax for patients nos. $1,3,4$, and 6 and a massive pleurisy for the 6 other patients. Patient no. 1 presented symptoms of a TSST-associated fever, hypotension, and developed skin rash with an acute pharyngitis and muscular pain and died 3 days after treatment. Patient no. 9 developed facial folliculitis and furuncles. Finally, 9 out of the 10 patients were dead 15 days after antimicrobial administration (Table 1). Only the 7-year old patient who received blood transfusion survived. A persisting cough remained after one month of treatment.

3.2. Isolation of S. aureus from Food, Hospital Personnel, and the Hospital Environment. Out of 221 samples obtained from hospital personnel, 21 (9.5\%) were positive for S. aureus. Also 38 (16.9\%) from 225 environmental sources and $65(43.3 \%)$ of the special cold food yielded S. aureus (Table 2).

3.3. Antibiograms. All the isolates were susceptible to the tested antibiotics except those sampled from patient no. 1 and one isolate from the environment, which were resistant to methicillin, tobramycin, kanamycin, gentamicin, and erythromycin.

3.4. Toxins Production. Concerning the patient isolates with the exception of patient no. 1, isolates from other patients produced PVL. In fact, isolates from patient no. 1 produced TSST-1. None of the tested isolates produced LukE-LukD leukotoxin or enterotoxins A, B, C, and D.

Among the 65 isolates of $S$. aureus from food sample, $49.2 \%$ of them were positive for PVL production (Table 2), while only $17.8 \%$ of the 38 isolates from the environment were positive for PVL production (Table 2). 33.3\% of the isolates from the hospital personnel were positive for PVL. No $S$. aureus isolated in this study produced the LukE-LukD leukotoxin or enterotoxins A, B, C, or D.

3.5. Pulsed Field Gel Electrophoresis. Pulsed field gel electrophoresis was repeated twice to identify pulsotypes composed of 11 to 15 SmaI DNA fragments for any of the PVLproducing isolates. The patients' PFGE profiles were distributed into four distinguished pulsotypes (Figure 2).

Isolates recovered from personnel, foods, and inanimate environment segregated into 16 different pulsotypes (Figure 2(b)), thus indicating the diversity of PVL-producing $S$. aureus isolates in the paediatric service. Finally, pulsotypes 


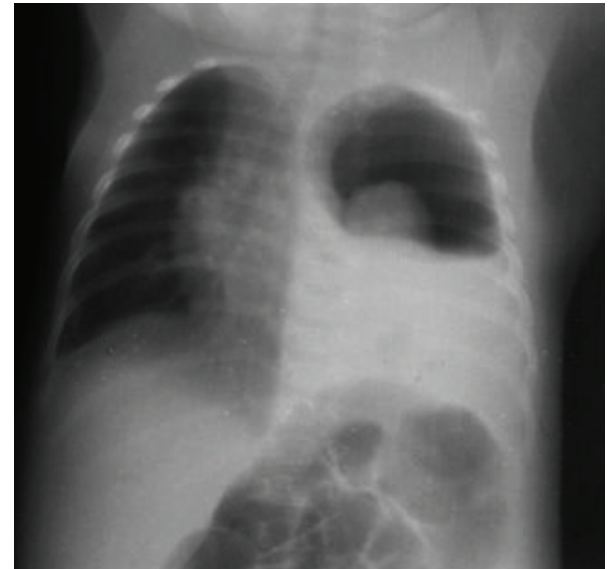

(a)

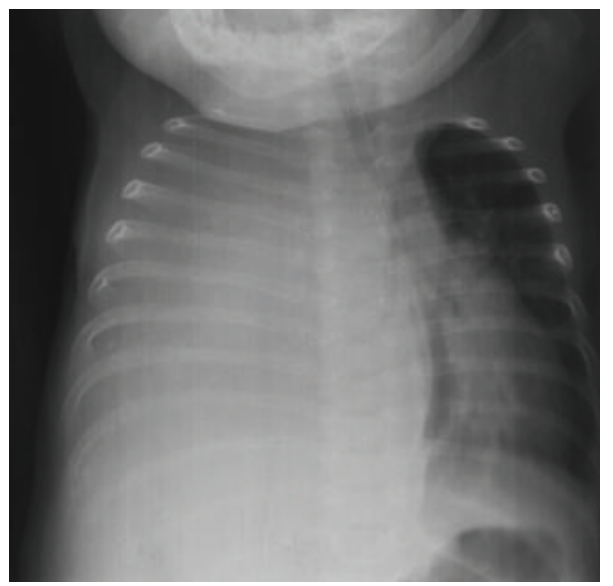

(c)

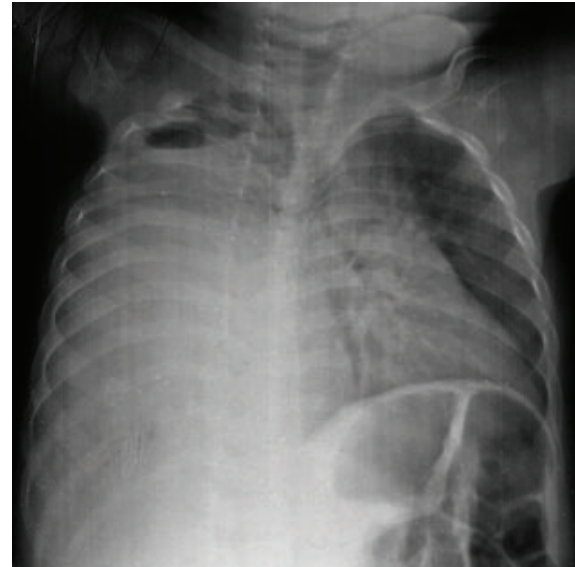

(b)

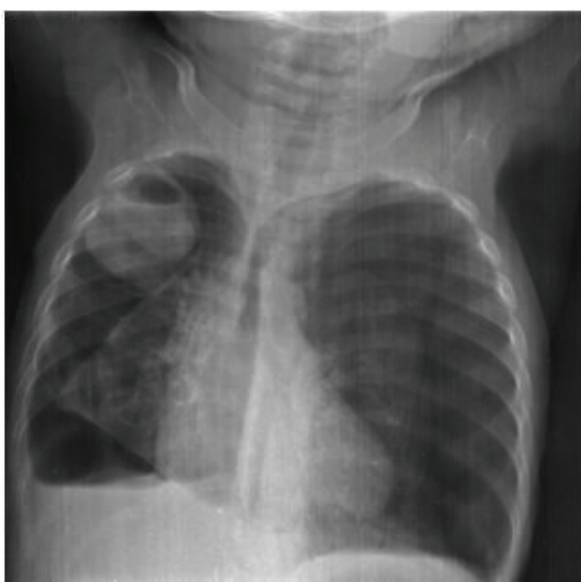

(d)

FIGURE 1: Radiography of thorax for patients (a) showing pyopneumothorax at left, (b) huge pleurisy from right and pneumothorax on left, (c) having a massive pleurisy at right, and (d) with a lobular pneumonia accompanied with a diaphragmatic costal out pouring.

AII, AIII, and 17 were seen from series of isolates obtained from both normal and special foods, nurses, and inanimate environment. Pulsotype 11 (Figure 2(b)) was observed in two nurses.

\section{Discussion}

Despite efforts from WHO and other organizations [31], pneumonia in children less than five (5) years remains an important cause of negative prognosis in developing countries. Therefore, infections with pneumonia are still a challenge worldwide. In August 20, 2009, the Infection Control Program at the $\mathrm{CHDZ} / \mathrm{C}$ was notified that a child hospitalized in the malnourished children unit developed unusual pneumonia and unfortunately died, thus leading to the present survey and the first documented outbreak of pneumonia due to PVL-producing S. aureus in Benin. We observed one of the most severe outbreaks of infant nosocomial pneumonia due to $S$. aureus with an incident rate of $57 \%$ in this study. All patients surveyed were previously treated for acute malaria or typhoid fever. The patients suffered from weight loss and anaemia, which led to the distribution of a specific meal before the onset of pneumonia.

These malnourished patients may have been predisposed to pneumonia because of these inherent factors. They were young, with severe anaemia, and most of them were confined to bed for a long time with diminished physiological defences. Inadequate cooking utensils contaminated equipment and poor personal hygiene which are common phenomena in most hospitals with limited resources. The contamination signs appeared rapidly after consumption of the special nutrients and were presumably caused by gastrooesophagus reflux that induced an increased risk of oro-pharyngeal colonization. Such contamination may have favored bacterial adhesion to epithelium, and thus, development of pneumonia.

Within 6 weeks of this study, 9 (90\%) out of the 10 patients suffering from $S$. aureus-associated pneumonia died, and, out of these patients, 8 died as a result of pneumonia associated with PVL-producing strains. This mortality was much higher than the 30 to $40 \%$ observed in USA by Stevens et al. [32] during nosocomial pneumonia due to Gram-positive 


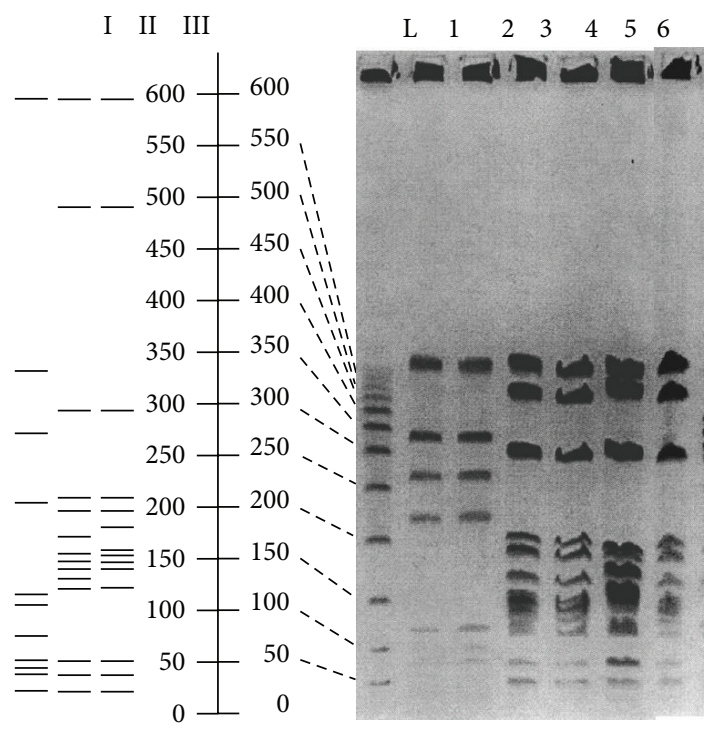

(a)

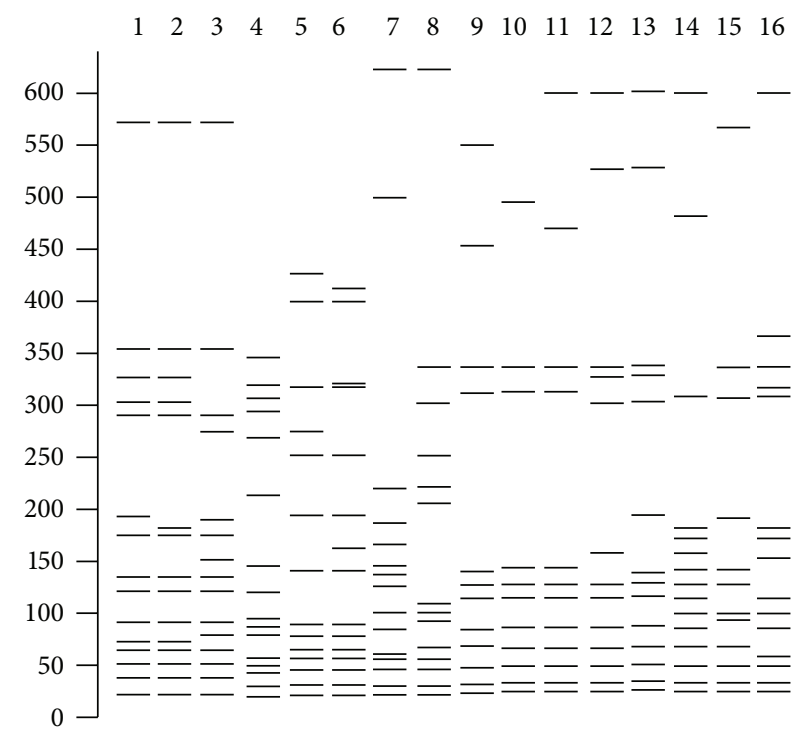

(b)

FIGURE 2: Schematic representations (AI to III) of PFGE SmaI fingerprints from the three major clones of S. aureus isolates obtained from the pneumonia outbreak (from 3 to 11 isolates per patient) are comparable with isolates obtained from some controlled foods (A1 to 6). Isolates issued from patient 1 and one of the controlled foods (lanes AI, A1, and 2), isolates issued from patients 2, 4, and 6, respectively (all comparable for patients 2 to 7, 9, and 10 and specific nurturing) (lanes AII, A3, 4, and 6); from isolates issued from patient 8 (lane AIII); and from the isolates issued from the community case of pneumonia observed in an adult at the same hospital during the study period. During the same period of the outbreak, other PVL-producing isolates were obtained from other foods, environment of the hospital service, and personnel (b); they distributed within 16 pulsotypes, which for some of them were retrieved from different points of environment and nurses. Other series of positive isolates mainly concerned foods.

bacterium but were comparable to results (75\%) reported in studies carried out in Europe [10,33].

In the recent years, necrotizing pneumonia has been described in children and young adults. Pneumonia caused by $S$. aureus in children less than 5 -year old still remains less studied than in teenagers and young adults. High prevalence of PVL-producing isolates was previously reported, especially in some sub-Saharan African countries [16, 17, 34]. The role of the environment in nosocomial spreading of $S$. aureus has been established [35]. In this study, it was alarming that, in a hospital environment, $60 \%$ of S. aureus isolated from food given to patients were PVL producers.

The examination of isolates from nine young patients infected with PVL-producing $S$. aureus showed only two strongly related pulsotypes (Figure 2, AII and III). The isolates from eight out of these nine patients could not be distinguished either by antibiogram, toxin production, or PFGE. Moreover, they could not be distinguished from the PFGE profile obtained from isolates collected from the specific foods served to patients (Figure 2, lanes AII, $\mathrm{A} 3,4$, and 6). In fact, the PVL-producing isolates from patient 8 harbored a fingerprint (AIII) comparable to 12 of the 14 SmaI DNA fragments representing the pulsotype II (Figure 2, lanes AIII, A5). Such a minor difference of about $15 \mathrm{~kb}$ may be due to the acquisition of a mobile genetic element and finally suggests clonal relationships between PVL-producing isolates collected from the eight patients. Patient no. 1 was suffering from a focal respiratory toxic shock syndrome, and the TSST1-producing isolates obtained from this patient remained comparable in antibiogram, toxin production, and pulsotype
(I) to the isolate from the controlled milk served to this patient, and others, at the early stage of his hospitalization, thus suggesting the origin of the infection to be the controlled milk (Figure 2, lanes AI, A1, and 2).

Some of the isolates from the hospital personnel belong to pulsotypes that were different from those found in patient no. 1 suggesting, therefore, that vectors of contamination may not only arise by breath or feeding. In this series of observations, contaminated foods, and any associated events have to be considered as potential vectors. Indeed, the patients with no infection on the date of admission to the hospital were infected with bacterium with characteristics similar to those identified in special foods served at the hospital, after being served this special diet. Pulsotype 11 (Figure 2(b)) was observed in two nurses but was not found on any food or food-handling personnel. This was the major difference with clones AII and AIII, which may have been spread over different foods and disseminated within the paediatric unit. However, one personnel was mainly positive for PVLproducing isolates once, while pneumonia cases elapsed over one month of the sampling period. Positive samples from the environment were taken from diverse sources (kitchen, doors, handles, nurse coats, beds, etc.). Thus, such observations may suggest that infections were mainly mediated by contaminated foods. As fragile patients probably cry, cough, and may have some difficulties of eating, gastrooesophagus reflux can be at the origin of these infections, and it should be considered as a major risk for respiratory infection caused by $S$. aureus. Patients weakened by neuromalaria probably are more sensitive to other infections than other 
hospital population groups. This fact suggests that no foods prepared under strict hygiene conditions can be a source of contamination. We assume that the primary source of this outbreak was either a contaminated foodstuff or a carrier nurse because contaminations of infant formula milk and oral enteral feeding are activities in which hygienic measures were deficient.

Considering the high diversity of PVL-producing isolates in the paediatric unit and the high incidence of these pathogenic strains in West Africa [16], cautions should be taken to avoid the spread of such strains at hospitals. For such reasons, community isolates may rapidly disseminate within a hospital service and become nosocomial.

The ability of TSST-1 to elicit necrotizing cytokines may account for one of the pathologies observed, but it may also suggest that PVL might not be the exclusive virulence factor associated with pneumonia, in some cases [36, 37]. Furthermore, this disease probably arose via contaminated food that also contained a TSST-1-producing pathogenic bacterium. On the basis of these observations, we can again suspect oral contamination by such virulent $S$. aureus isolates in infants, especially when they were also infected by underlying diseases such as malaria or typhoid fever which are frequent diseases in developing countries. The susceptibility of malnourished children, coupled with insufficient infection control measures, contributed to this outbreak.

The presence of staphylococcal pneumonia in the community and the higher prevalence of PVL-producing isolates in sub-Saharan Africa than in Europe $[16,34]$ are serious reasons for promotion of hygiene and good practices in hospitals. This will diminish the risk of the spread of such isolates in the hospital. It also appears that individual hygiene needs to be emphasized both at hospital and in the community, as well as treatment of diseases such as malaria in infants.

\section{Conclusion}

In conclusion, series of fatal and nosocomial pneumonia revealed the sensitiveness of infants to necrotising pneumonia caused by PVL-producing $S$. aureus when they are already suffering from malaria, typhoid fever, or marasmus. However, other toxin-producing isolates may also be responsible for pneumonia. PFGE typing indicated that hospital special foods were repeatedly colonized by PVL-producing S. aureus strains. The lack of epidemiological data about antimicrobial resistance of these bacteria and the occurrence of community-acquired infections caused by these bacteria point to the urgent need for further studies to acquire knowledge about bacterial epidemiology in developing countries.

\section{Conflict of Interests}

The author declare that they have no conflict of interests.

\section{Acknowledgments}

The authors thank CHDZ/C personnel for their rigorous participation in this study, D. Keller for his skilful technical assistance. Thanks also due to Professor M. Delmée, Dr. A. Simon (Louvain Catholic University, Belgium) for their contribution to antibiograms.

\section{References}

[1] G. Prévost, "Toxins in Staphylococcus aureus pathogenesis," in Microbial Toxins: Molecular and Cellular Biology, P. T. Norfolk, Ed., pp. 243-283, Horizon Bioscience Press, Oxford, UK, 2005.

[2] S. K. Pingleton, J. Y. Fagon, and K. V. Leeper Jr., "Patient selection for clinical investigation of ventilator-associated pneumonia. Criteria for evaluating diagnostic techniques," Chest, vol. 102, supplement 1, pp. 553S-556S, 1992.

[3] M. Wiese-Posselt, D. Heuck, A. Draeger et al., "Successful termination of a furunculosis outbreak due to $l u k S$-lukF-positive, methicillin-susceptible Staphylococcus aureus in a German village by stringent decolonization, 2002-2005," Clinical Infectious Diseases, vol. 44, no. 11, pp. 88-95, 2007.

[4] L. Baba-Moussa, H. Sina, J. Scheftel et al., "Staphylococcal panton-valentine leucocidin as a major virulence factor associated to furuncles," PLoS ONE, vol. 6, no. 10, Article ID e25716, 2011.

[5] I. Le Thomas, P. Mariani-Kurkdjian, A. Collignon et al., "Breast milk transmission of a Panton-Valentine leukocidin-producing Staphylococcus aureus strain causing infantile pneumonia," Journal of Clinical Microbiology, vol. 39, no. 2, pp. 728-729, 2001.

[6] B. A. Sanford, V. L. Thomas, M. A. Ramsay, and T. O. Jones, "Characterization of clinical strains of Staphylococcus aureus associated with pneumonia," Journal of Clinical Microbiology, vol. 24, no. 1, pp. 131-136, 1986.

[7] A. Caillault-Sergent, J. Illinger, O. Dauwalder, P. Nesme, and L. Argaud, "Necrotising community-acquired pneumonia due to Panton-Valentine leukocidin-secreting Staphylococcus aureus: a rare diagnosis to be evoked," Presse Medicale, vol. 40, no. 10, pp. 966-970, 2011.

[8] P. R. Davies, E. A. Wagstrom, and J. B. Bender, "Lethal necrotizing pneumonia caused by an ST398 Staphylococcus aureus strain," Emerging Infectious Diseases, vol. 17, no. 6, pp. 1152-1153, 2011.

[9] P. Dufour, Y. Gillet, M. Bes et al., "Community-acquired methicillin-resistant Staphylococcus aureus infections in France: emergence of a single clone that produces Panton-Valentine leukocidin," Clinical Infectious Diseases, vol. 35, no. 7, pp. 819$824,2002$.

[10] Y. Gillet, B. Issartel, P. Vanhems et al., "Association between Staphylococcus aureus strains carrying gene for Panton-Valentine leukocidin and highly lethal necrotising pneumonia in young immunocompetent patients," The Lancet, vol. 359, no. 9308, pp. 753-759, 2002.

[11] Y. Gillet, B. Issartel, P. Vanhems et al., "Severe staphylococcal pneumonia in children," Archives de Pediatrie, vol. 8, supplement 4, pp. 742s-746s, 2001.

[12] M. Tseng, B. Wei, W. Lin et al., "Fatal sepsis and necrotizing pneumonia in a child due to community-acquired methicillinresistant Staphylococcus aureus: case report and literature review," Scandinavian Journal of Infectious Diseases, vol. 37, no. 6-7, pp. 504-507, 2005.

[13] H. Sax, K. Posfay-Barbe, S. Harbarth et al., "Control of a cluster of community-associated, methicillin-resistant Staphylococcus aureus in neonatology," Journal of Hospital Infection, vol. 63, no. 1, pp. 93-100, 2006. 
[14] J. M. Voyich, M. Otto, B. Mathema et al., "Is Panton-Valentine leukocidin the major virulence determinant in communityassociated methicillin-resistant Staphylococcus aureus disease?" Journal of Infectious Diseases, vol. 194, no. 12, pp. 1761-1770, 2006.

[15] World Health Organization, World Health Report 2005-Makes Every Mother and Child Count, pp. 190-191, World Health Organization, Geneva, Switzerland, 2005.

[16] L. Baba-Moussa, A. Sanni, A. Y. Dagnra et al., "Approche épidémiologique de l'antibiorésistance et de la production de leucotoxines par les souches de Staphylococcus aureus isolées en Afrique de l'Ouest," Médecine et Maladies Infectieuses, vol. 29, no. 11, pp. 689-696, 1999.

[17] A. Y. Dagnra, A. Tristan, Y. Gillet, and J. Étienne, "New emerging Staphylococcus aureus strains," Revue du Praticien, vol. 54, no. 10, pp. 1053-1058, 2004.

[18] T. Adam, S. S. Lim, S. Mehta et al., "Achieving the millennium development goals for health: cost effectiveness analysis of strategies for maternal and neonatal health in developing countries," British Medical Journal, vol. 331, no. 7525, pp. 11071112, 2005.

[19] O. Tagbo, O. Uchenna, and H. Anthony, "Childhood parapneumonic pleural effusion in Enugu," The Nigerian Postgraduate Medical Journal, vol. 12, no. 1, pp. 28-32, 2005.

[20] M. L. Speck, Compendium of Methods for Microbiological Examination of Foods, pp. 277-328, American Public Health Association, Washington DC, USA, 1976.

[21] G. Lancette and R. Bennett, "Staphylococcus aureus and staphylococcal enterotoxins," in Compendium of Methods for the Microbiological Examination of Foods, F. Downes and K. Ito, Eds., pp. 387-403, Apha, Washington, DC, USA, 2001.

[22] P. Riegel, M. Archambaud, D. Clavé, and M. Vergnaud, Bactérie de culture et d'identification difficiles, Biomérieux, Nancy l'Etoile, France, 2006.

[23] P. A. Wayne, "Performance standards for antimicrobials susceptibility testing," NCCLS, 10th Informational Supplement M100S10, National Committee for Clinical Laboratory Standards, 2002.

[24] C. J. Soussy, "Recommandations du Comité de l'Antibiogramme de la Société Française de Microbiologie: Communiqué 2006," p. 49, 2006, http://www.sfm-microbiologie.org/UserFiles/file/ CASFM/casfm_2006.pdf.

[25] A. Gravet, D. A. Colin, D. Keller, R. Girardot, H. Monteil, and G. Prévost, "Characterization of a novel structural member, LukELukD, of the bi-component leucotoxins family," FEBS Letters, vol. 436, no. 41, pp. 202-208, 1998.

[26] A. Gravet, M. Rondeau, C. Harf-Monteil et al., "Predominant Staphylococcus aureus isolated from antibiotic-associated diarrhea is clinically relevant and produces enterotoxin A and the bicomponent toxin LukE-LukD," Journal of Clinical Microbiology, vol. 37, no. 12, pp. 4012-4019, 1999.

[27] A. Gravet, P. Couppié, O. Meunier et al., "Staphylococcus aureus isolated in cases of impetigo produces both epidermolysin A or $\mathrm{B}$ and LukE+LukD in $78 \%$ of 131 retrospective and prospective cases," Journal of Clinical Microbiology, vol. 39, no. 12, pp. 43494356, 2001.

[28] G. Prevost, B. Pottecher, M. Dahlet, M. Bientz, J. M. Mantz, and Y. Piemont, "Pulsed field gel electrophoresis as a new epidemiological tool for monitoring methicillin-resistant Staphylococcus aureus in an intensive care unit," Journal of Hospital Infection, vol. 17, no. 4, pp. 255-269, 1991.
[29] M. de Onis, C. Monteiro, J. Akre, and G. Clugston, “The worldwide magnitude of protein-energy malnutrition: an overview from the WHO global database on child growth," Bulletin of the World Health Organization, vol. 71, no. 6, pp. 703-712, 1993.

[30] A. Ashworth, S. Khanum, A. Jackson, and C. Schofield, "Directives pour le traitement hospitalier des enfants sévèrement malnutris," Bibliothèque de l'OMS, Classification NLM WS 115, 2004.

[31] WHO, "Donnons sa chance à chaque mère et à chaque enfant," Rapport sur la Santé dans le Monde RHR-04. 10, 2005, http:// www.who.int/whr/2005/fr/.

[32] R. M. Stevens, D. Teres, J. J. Skillman, and D. S. Feingold, "Pneumonia in an intensive care unit. A 30 month experience," Archives of Internal Medicine, vol. 134, no. 1, pp. 106-111, 1974.

[33] S. Petros, B. Eggers, M. Heuer et al., "Severe community acquired pneumonia due to Staphylococcus aureus," Intensive Care Medicine, vol. 24, no. 2, p. 189, 1998.

[34] P. Couppie, B. Cribier, G. Prevost, E. Grosshans, and Y. Piemont, "Leukocidin from Staphylococcus aureus and cutaneous infections: an epidemiologic study," Archives of Dermatology, vol. 130, no. 9, pp. 1208-1209, 1994.

[35] D. Talon, "The role of the hospital environment in the epidemiology of multi-resistant bacteria," Journal of Hospital Infection, vol. 43, no. 1, pp. 13-17, 1999.

[36] M. Labandeira-Rey, F. Couzon, S. Boisset et al., "Staphylococcus aureus Panton-Valentine leukocidin causes necrotizing pneumonia," Science, vol. 315, no. 5815, pp. 1130-1133, 2007.

[37] J. B. Wardenburg, T. Bae, M. Otto, F. R. DeLeo, and O. Schneewind, "Poring over pores: $\alpha$-hemolysin and PantonValentine leukocidin in Staphylococcus aureus pneumonia," Nature Medicine, vol. 13, no. 12, pp. 1405-1406, 2007. 


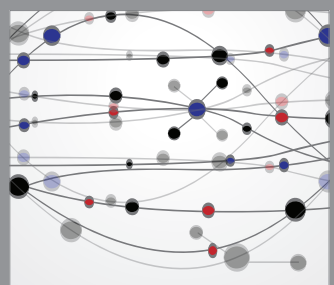

The Scientific World Journal
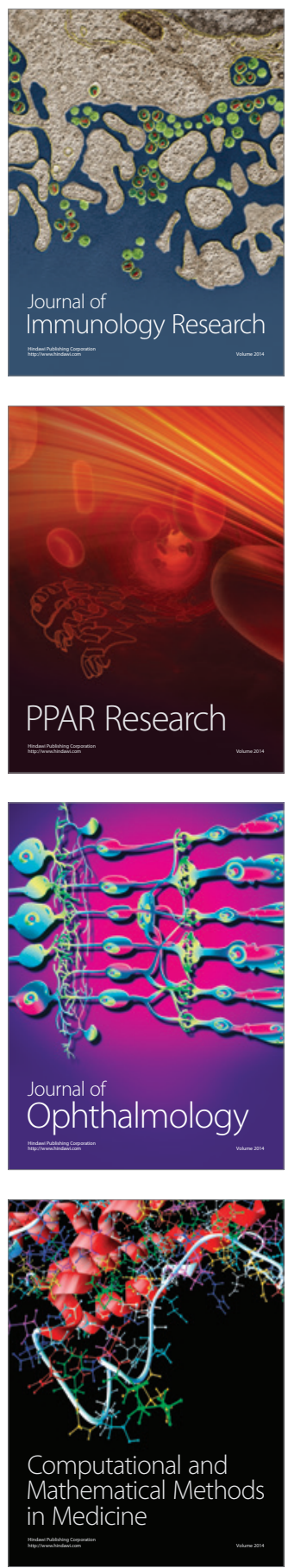

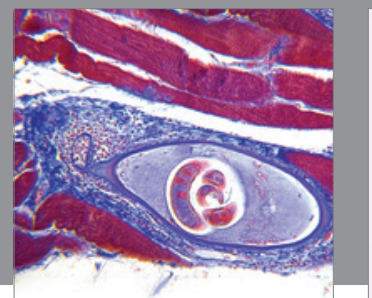

Gastroenterology

Research and Practice
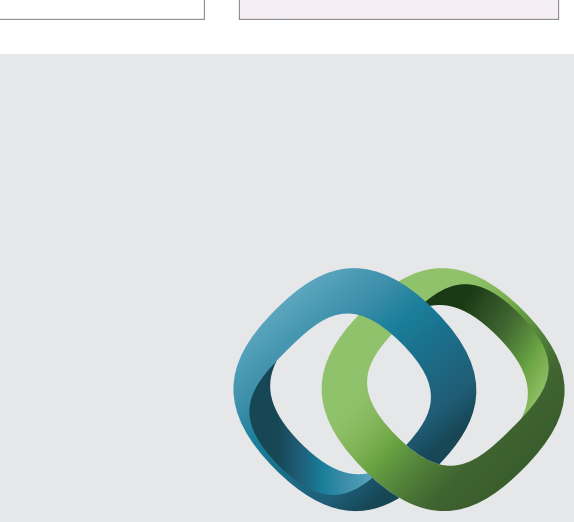

\section{Hindawi}

Submit your manuscripts at

http://www.hindawi.com
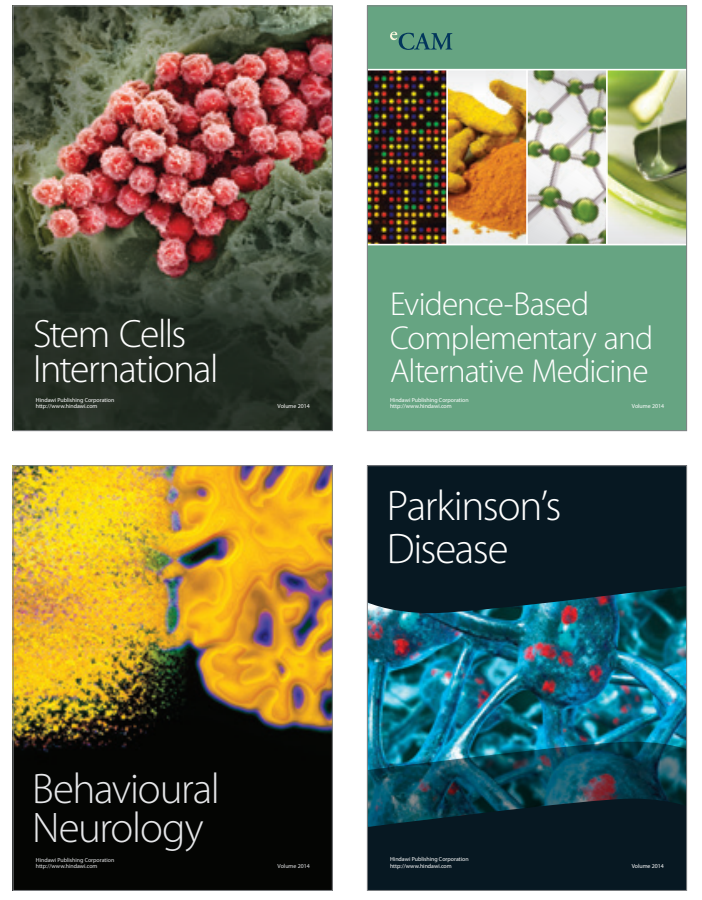
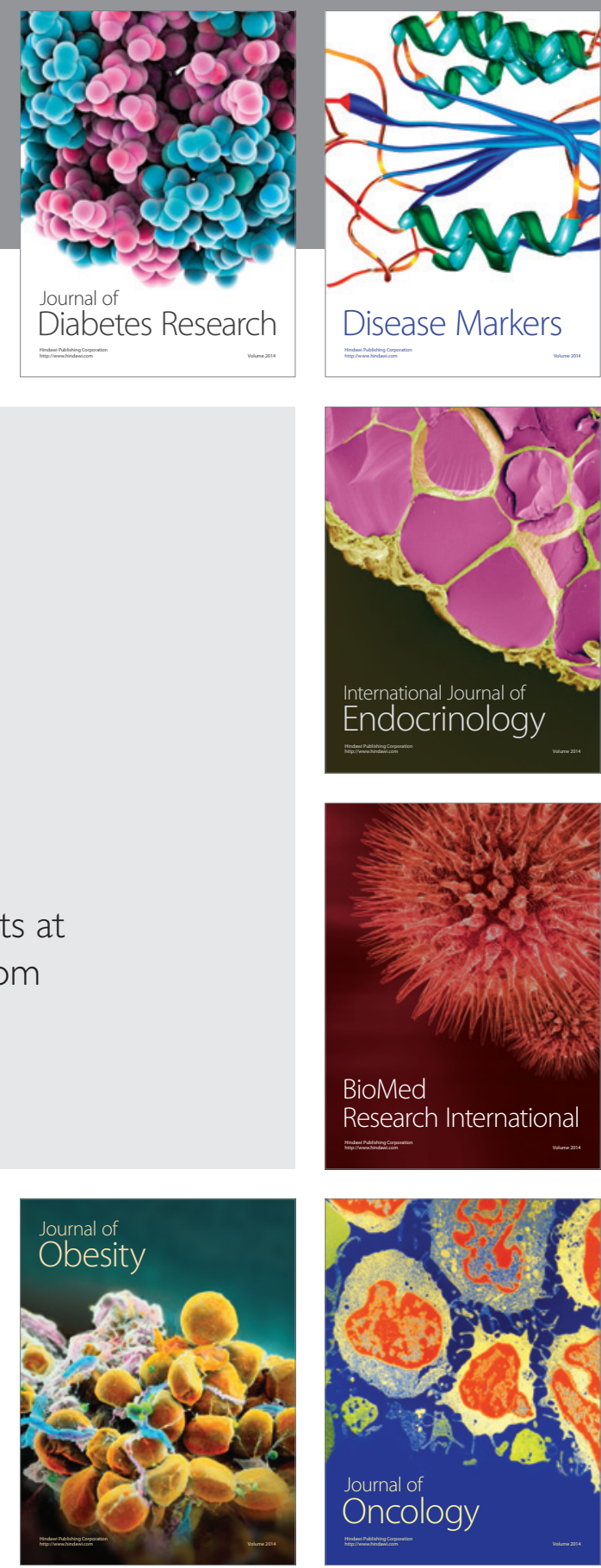

Disease Markers
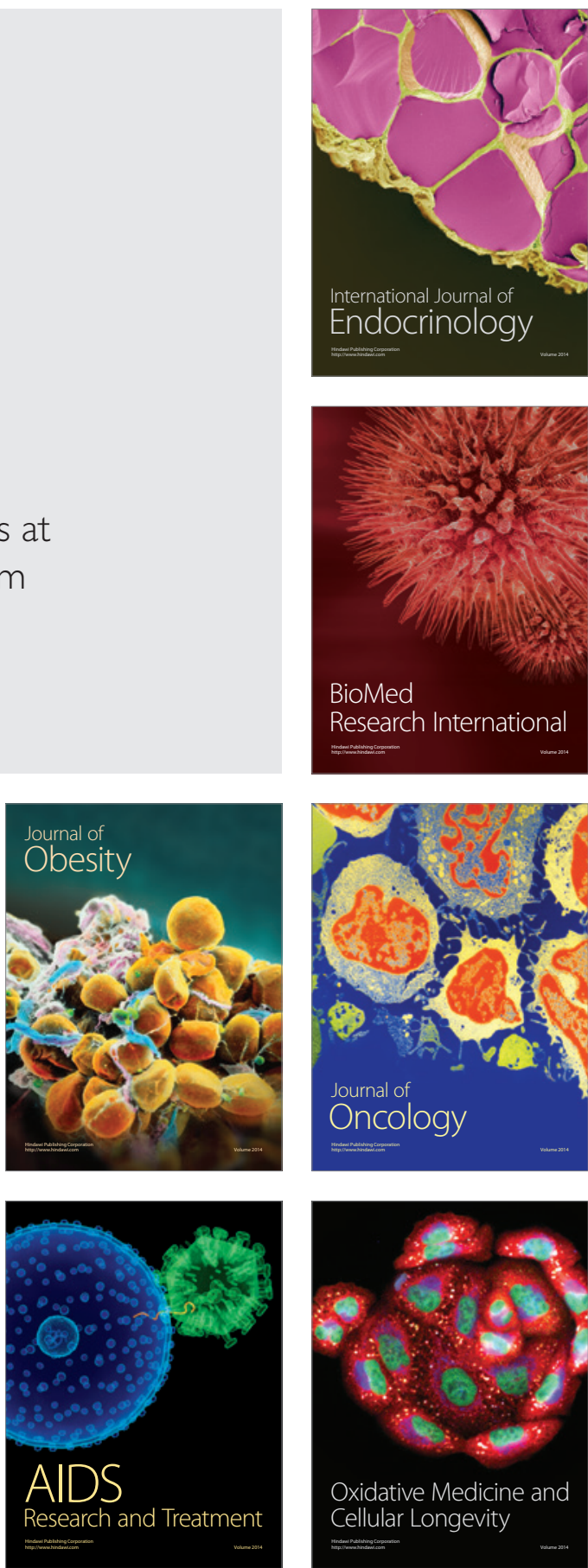